\title{
CULTURA POLÍTICA E PARTICIPAÇÃO SOCIAL: AS ONGs AMBIENTALISTAS E A GESTÃO AMBIENTAL DA CIDADE DE JOÃO PESSOA/PB
}

\author{
Vivian Maite Castro ${ }^{1}$
}

\begin{abstract}
RESUMO. A cidade de João Pessoa é uma das capitais brasileiras que ainda conserva relevantes áreas de Mata Atlântica, e o movimento ambientalista local conquistou causas importantes que contribuíram para este diferencial. A crise da democracia representativa promove a organização dos movimentos sociais, que buscam uma maior participação nas decisões políticas, via instâncias de consulta, tais como conselhos, comitês e o orçamento participativo. Este artigo objetiva avaliar os resultados da participação social nas instâncias de consulta democrática na região Nordeste do Brasil, considerando sua história e cultura política, apresentando resultados de uma pesquisa de campo focada na atuação das ONGs ambientalistas de João Pessoa. O trabalho analisou o discurso oficial do governo sobre as ONGs, e a autopercepção delas sobre suas atuações diante das decisões políticas. Percebeu-se que inexiste uma relação e um diálogo com vias à promoção do interesse coletivo. Há um conflito entre esses atores, que prejudica a transversalidade da temática ambiental, resultando em embates e perdas de Mata Atlântica na cidade. Por outro lado, há uma preocupação de ambos com esses atributos ambientais que promovem qualidade de vida, e associam João Pessoa ao rótulo de cidade verde.
\end{abstract}

Palavras Chave - Ambientalismo; Gestão Municipal; Instâncias de Participação; ONGs.

\section{POLITICAL CULTURE AND SOCIAL PARTICIPATION: THE ENVIRONMENTAL NGOS AND THE ENVIRONMENTAL MANAGEMENT IN THE CITY OF JOÃO PESSOA/PB}

\begin{abstract}
The city of João Pessoa is one of the Brazilian capitals that still conserves important areas of Atlantic Forest, and the local environmental movement has conquered important causes that contributed to this differential. The crisis of representative democracy promotes the organization of social movements, which seek greater participation in political decisions, through consultation bodies such as councils, committees and participatory budgeting. This article aims to evaluate the results of social participation in the instances of democratic consultation in the Northeast region of Brazil, considering its history and political culture, presenting results of a field research focused on the actions of environmental NGOs in João Pessoa. The paper analyzed the government's official discourse on NGOs, and their self-perception about their actions in the face of political decisions. It was perceived that there is no relationship and dialogue with the promotion of collective interest. There is a conflict between these actors, which harms the transversality of the environmental theme,
\end{abstract}

\footnotetext{
${ }^{1}$ Universidade Federal da Paraíba
} 
resulting in impacts and losses in the city's Atlantic Forest. On the other hand, there is a concern of both with these environmental attributes that promote quality of life, and associate João Pessoa with the green city label.

Key Words - Environmentalism; Municipal Management; Participative Spaces; NGOs.

\section{INTRODUÇÃO}

O meio ambiente se configura como um campo de conhecimento interdisciplinar inserido no contexto fragmentado da sociedade moderna. Está presente em todos os setores e divisões estabelecidas pelo Estado e pela sociedade, figurando como componente importante em diversas organizações políticas e sociais. A existência humana é condicionada pela qualidade do ambiente, devendo ser um aspecto transversal nas discussões governamentais.

Nesta pesquisa, Organização Não Governamental (ONG) é um coletivo do terceiro setor, legalmente instituído, com missão definida e representando a defesa de interesses comuns. O terceiro setor, no mundo globalizado, trouxe um novo equilíbrio às forças do Estado e do mercado, ao expressar as demandas da sociedade sem objetivar o lucro, por isso sendo também conhecidas como organizações sem fins lucrativos. Já movimento social é definido como grupos que se unem por interesses comuns, porém não são instituídos legalmente.

$\mathrm{Na}$ história do ambientalismo no Brasil e no mundo, desenvolvimento e progresso sempre caminharam distantes, como pólos inconciliáveis. A idéia de aliança entre desenvolvimento e meio ambiente surgiu em 1987, com o conceito de desenvolvimento sustentável ${ }^{2}$. Ainda assim, quase três décadas após, a adoção de nova mentalidade; de novos meios de produção e consumo, além de novas atitudes para com a natureza, ainda é um desafio. A evolução tecnológica é vista como a salvação para a manutenção do modelo vigente, embora já tenhamos iniciado um processo de declínio, com a escassez de recursos naturais vitais para a sobrevivência, como a água; o aumento da temperatura e da frequência de desastres; o rápido desaparecimento de espécies, comprometendo a biodiversidade e o equilíbrio planetário; e a escassez de recursos naturais, que antes parecia um cenário futurista.

\footnotetext{
${ }^{2}$ Relatório Brutdland, 1987.
} 
Diante desse panorama, agravado com o passar dos anos, as organizações não governamentais (ONGs) adquiriram maior legitimidade, respeito e status como representação dos interesses comuns, denunciando ou participando da construção de medidas e políticas mitigadoras. A partir do questionamento: "Quais são as ONGs ambientalistas da cidade de João Pessoa, e como ocorre a relação destas com o poder público, já que representam interesses comuns à sociedade, na formulação e execução de políticas públicas de meio ambiente?"; deu-se a inquietude central deste trabalho

O mesmo debruça-se sobre a dificuldade de garantir uma abordagem transversal da pauta ambiental nas tomadas de decisões por parte do poder público visando o desenvolvimento sustentável. Avalia, também, os resultados da abertura à participação da sociedade nas instâncias de consulta pública na cidade de João Pessoa, como conselhos, comitês e o orçamento participativo, e como isto reflete no rótulo popularmente adotado de cidade verde.

Pretendemos destacar o caráter qualitativo da pesquisa, apresentando as motivações, valores e interesses que têm orientado as ONGs ambientalistas de João Pessoa, e o resultado da participação destas nas instâncias de participação. Além disso, como o governo percebe essa atuação e define sua relação com as ONGs.

\section{A cultura política no nordeste do Brasil}

A cultura brasileira evidencia traços marcantes que influenciaram a formação de uma história política nacional. Cultura política pode ser entendida como um conjunto de valores, orientações e atitudes políticas, fruto dos processos de socialização e da experiência pessoal dos cidadãos (MOISÉS, 1992).

No Brasil, temos que considerar outras características específicas da nossa 'brasilidade' nesse processo. Como afirma DaMatta (1986), nossa cultura política foi delineada por meio do clientelismo, familismo, nepotismo e o famoso "jeitinho brasileiro”. O Nordeste é uma região caracterizada pelo destaque dado à vida política na sociedade, devido à dependência dos empregos públicos em locais onde o setor de bens e serviços é restrito e a indústria incipiente.

Segundo Avritzer (2007), a construção da política nessa região engloba elementos familiares e estruturas hierárquicas de sua própria formação. Ele cita a 
literatura de Gilberto Freyre, que descreve o contraste de relações existentes no Nordeste, baseado no estabelecimento de uma sociedade patriarcal e hierárquica, fato que propicia relações políticas específicas, típica de sociedades eminentemente agrárias.

Estas relações permeadas por favorecimentos e pela pouca autonomia da sociedade perpetuam governos autoritários, restritivos à participação social, e ocupados por transmissão geracional das famílias tradicionais no poder. Na Paraíba, é comum encontramos relações de parentesco, apadrinhamento, troca de favores e o predomínio das famílias tradicionais, que se revezam ocupando espaços políticos e cargos públicos. Há uma predominância da cultura patrimonialista que, segundo Sorj (2006, p. 13), "caracteriza-se pela apropriação privada dos recursos do Estado, seja pelos políticos ou funcionários públicos, seja por setores privados”, comprometendo a efetivação do ideal democrático.

No Brasil, o predomínio do personalismo, e o estrangulamento dos espaços de participação, provocaram, a apatia e o distanciamento da sociedade. Os movimentos sociais, apesar de estimularem a participação, não conseguiram extinguir completamente o clientelismo da cultura brasileira. Segundo Fernandes (2004), muitos movimentos de ação coletiva foram cooptados pelo Estado. Eles passaram a negociar, tendo o fantasma da manipulação e o populismo do Estado sempre presentes.

Em João Pessoa, com a eleição de um prefeito originário dos movimentos sociais em 2005, a prefeitura adotou uma nova forma de gestão, dando mais espaço às ONGs e criando o Orçamento Participativo. Por outro lado, antigos militantes foram nomeados como gestores, e passaram a ocupar cargos públicos, promovendo avanços em alguns setores e contribuindo, também, para negociações entre o movimento social e o poder público. "Cidadania e clientelismo são faces da mesma moeda, vai variar de acordo com o tipo de relação que será estabelecida entre os movimentos e o governo, e partidos, por intermédio de órgãos e agências competentes" (FERNANDES, 2004, p. $80)$.

O cenário reflete o passado clientelista, não participativo e com política elitista, porém aponta a possibilidade de novos arranjos institucionais com uma gestão inovadora, assinalando uma maior demanda por participação junto ao poder público, e este, por sua vez, em responder a uma sociedade mais informada sobre os seus direitos. 


\section{Gestão tradicional $x$ gestão inovadora}

De acordo com Rolnik e Somekh (2000), a cidade de João Pessoa voltou-se para processos de modernização gerencial da gestão pública, quando da transferência do poder decisório aos municípios. A gestão municipal apresentou mudanças estruturantes necessárias e positivas, que provocaram transformações na cidade a partir de 2005. Entretanto, após esses anos, faz-se necessário um avanço na descentralização do poder e nas oportunidades de participação social nas decisões públicas.

Dois fatores contribuem para isso: o perfil Estadocêntrico (SILVA, 2004) da população, e resquícios da cultura política clientelista, a qual observa as decisões políticas de maneira distante, não participando de instâncias como os Conselhos, Comitês e o Orçamento Participativo. Por um lado, o Estado promove políticas públicas assistencialistas e protecionistas, doando bens materiais e direitos sociais, objetivando, na verdade, desmobilizar os movimentos socioambientais e manter o controle sobre a população, como se o poder público estivesse, assim, cumprindo seu papel democrático (SILVA; SOUZA-LIMA, 2010). Por outro, tem-se um governo dito democráticoparticipativo, direcionado para o modelo inovador de gestão, porém que constitui instâncias de participação por obrigatoriedade legal, que funcionam, muitas vezes, como espaços de legitimação das decisões que lhe interessam.

Embora as relações clientelistas e de cooptação ocorram, os processos de participação e transformação da cultura política em João Pessoa demonstram estar em curso, com alguns avanços. O empoderamento e a compreensão da importância destas instâncias são processos que necessitam de motivação constante, para que haja cobrança popular e ocupação destes espaços com qualidade nas discussões, modificando, aos poucos, a cultura política local. Entretanto, as relações internas e intragovernamentais ainda se assemelham ao modelo de gestão tradicional, vertical, hierarquizado, burocrático e autoritário, apenas com momentos de participação, descentralização e horizontalidade. Esse processo de transformação é trabalhoso e lento, além de ser permeado por interesses difusos.

A sociedade adotou uma postura mais participativa e consciente, o que, para Moisés (1995), ressalta a formação de opinião pública mais atenta e interessada na 
política do país. Também Gohn (2011) afirma que a participação nas políticas públicas é fruto da luta por direitos sociais, cidadania e melhores condições de vida.

A construção de redes de coordenação horizontal, nas ações da esfera local, bem como a postura dos funcionários públicos, poderá contribuir para a evolução do município. No entanto, percebemos que os modelos tradicionais e inovadores se mesclam na cidade de João Pessoa, com pequenos e temporários focos de mudanças para um modelo inovador, porém ainda com predomínio do tradicional.

\section{Instrumentos de gestão: orçamento democrático, conselhos gestores e comitês}

Num contexto de dar transparência aos gastos públicos, a prefeitura instituiu a Secretaria da Transparência Pública e a Coordenadoria do Orçamento Democrático (OD) (SILVA, 2011). Contudo, esta instância decide apenas 3\% do orçamento. As assembleias apresentam as demandas gerais da população, que geralmente abordam as áreas de geração de emprego e renda, educação, saúde e infraestrutura. A temática ambiental não configura como prioridade. Pesquisa de campo, Castro (2012).

Já os Conselhos emergem da busca por uma nova institucionalidade pública. Segundo Gohn (2011), a participação “objetiva o fortalecimento da sociedade civil, não para que esta participe da vida do Estado, mas para fortalecê-la e evitar as ingerências do Estado - seu controle, tirania e interferência na vida dos indivíduos" (GOHN, 2011, p. 18). Inscritos na Constituição Federal de 1988, e amparados por leis nacionais, eles constituem-se como "instrumentos de expressão, representação e participação; em tese, eles são dotados de potencial de transformação política” (GOHN, 2011, p. 89).

A participação política é, por si só, uma forma de exercício de poder, pois supõe uma relação da gestão pública com os atores envolvidos, que defendem seus interesses e valores. Entretanto, nem sempre esses atores representam o interesse coletivo e, muitas vezes, suas atuações expressam valores pessoais, capacidades e condições políticas nas quais estão envolvidos. Portanto, a participação é um processo contraditório, permeado pelas características do sujeito que participa e pelas instâncias (TEIXEIRA, 1997).

Por outro lado, a participação depende de lógicas que se distinguem em seus diferentes atores. Enquanto o poder público estabelece-se a partir da racionalidade e da 
competitividade, a sociedade civil, movimentos e ONGs atuam a partir da lógica do consenso e da solidariedade.

Na Paraíba, a cultura política e a pouca organização comprometem a efetiva participação da sociedade nos conselhos. Em João Pessoa, as instâncias ambientais existentes são: o Comitê Gestor Projeto Orla, coordenado pela Superintendência do Patrimônio da União; o Conselho de Proteção Ambiental (COPAM) coordenado pelo Governo Estadual; e o Conselho Municipal do Meio Ambiente (COMAM), presidido pela Secretaria de Meio Ambiente de João Pessoa (SEMAM).

A existência de dois conselhos dá-se devido à autonomia da prefeitura em licenciar obras de impacto local, que necessitam da deliberação do Conselho Municipal, segundo a legislação federal. Já o Conselho Estadual atua sobre o licenciamento de obras de maior impacto e influência estadual, considerando também as obras de impacto local de todos os outros municípios que ainda não são aptos a fazer o licenciamento ambiental $^{3}$. A escolha do órgão é uma opção do empreendedor, geralmente feita de acordo com o tempo de espera pela licença, e pelo valor cobrado. Pesquisa de campo, Castro (2012).

Ambos conselhos pautam suas reuniões exclusivamente na discussão e aprovação de licenças ambientais, geralmente as mais controversas e com maior dano ambiental, que são analisadas por técnicos do órgão e distribuídas aos conselheiros para eventuais considerações e posterior aprovação. Demandas sociais, questionamentos e propostas de projetos são inexistentes. Pesquisa de campo, Castro (2012).

No COPAM, há uma única ONG presente, a Associação Paraibana dos Amigos da Natureza (APAN), indicação legal contida na Constituição do Estado da Paraíba de 1989. Bastante antiga e reconhecida por sua atuação ambiental no campo jurídico e de denúncia, segundo a pesquisa de campo, a APAN é vista com desagrado pelos gestores públicos, devido aos seus posicionamentos contrários ao governo. Isola-se em seus questionamentos pela disparidade de assentos entre representantes do governo, das indústrias e entidades de classe (ENTREVISTA 8, APAN, 2012)

\footnotetext{
3 Com a Lei Complementar 140/2011, que define as competências dos estados e municípios, especialmente no que tange o licenciamento ambiental, a tendência é a estruturação destes para o cumprimento da legislação, ampliando a arrecadação dos municípios e a quantidade de conselhos municipais deliberativos.
} 
O Comitê Gestor Projeto Orla também é formado por representantes do governo e da sociedade civil, e constituiu-se a partir de um projeto nacional, desenvolvido pelos Ministérios do Meio Ambiente e Planejamento e Gestão, por meio da Secretaria de Patrimônio da União. A adesão do Estado é voluntária e objetiva elaborar e implementar a gestão integrada nas orlas marítima e fluvial. O comitê realizou algumas obras e intervenções na orla da capital, estruturando áreas turísticas, restaurantes e quiosques. Entretanto, o mesmo encontra-se inoperante desde 2010, quando mudanças internas na prefeitura, devido à campanha eleitoral, modificou secretários e as prioridades do governo (ENTREVISTA 12, SEMAM, 2012).

Em João Pessoa, as instâncias de participação ambiental refletem a pouca assimilação do poder público acerca do modelo inovador de gestão. O diálogo se reduz a procedimentos administrativos e cumprimento da legislação, do que como espaço de participação de fato da sociedade. Ainda, quando as decisões são fortemente questionadas, o poder público manipula o processo e garante a aprovação de acordo com seu interesse (ENTREVISTA 12, SEMAM, 2012).

Formas de garantir a participação da sociedade civil e das ONGs englobam uma profunda transformação e atualização da legislação e das representações existentes. Os conselhos, comitês e orçamentos participativos necessitam se tornar instâncias reais de envolvimento da sociedade e deliberação conjunta de decisões públicas. Entretanto, articular esses espaços e mobilizar a sociedade requer um trabalho longo e persistente, além de esforços da parte das ONGs, do poder público e da sociedade.

\section{Metodologia de pesquisa}

A partir do questionamento: "Quais são as ONGs ambientalistas de João Pessoa, e como ocorre a relação destas com o poder público, já que representam interesses comuns à sociedade, na formulação e execução de políticas públicas de meio ambiente?"; deu-se a inquietude central deste trabalho. Por perceber que boa parte da sociedade desconhece as ONGs atuantes em João Pessoa, tampouco compreende seus trabalhos de cunho político, que é a representação nas instâncias de participação. Por outro lado, nem todas as ONGs empenham-se neste papel, algumas sequer realizam 
parcerias com o poder público, além daquelas que se posicionam contrárias às iniciativas do governo.

Segundo Moresi (2003), os métodos qualitativos são recomendados quando o objeto de estudo é complexo, possui natureza social, e sua compreensão sociocultural é um elemento importante ao trabalho. Neste caso, o papel das ONGs, como representação dos interesses comuns da sociedade, figura como elemento central deste estudo. Devido à proporção de ONGs atuantes para uma cidade de médio porte como João Pessoa, o universo da pesquisa, embora tenha se configurado como pequeno, foi bastante representativo para a finalidade deste estudo.

A pesquisa de campo foi realizada a partir de entrevistas presenciais qualitativas com gestores públicos de meio ambiente e ONGs ambientalistas, não excluindo aquelas que incorporam a temática ambiental em atividades secundárias e complementares. Assim, foi entrevistado um representante de cada ONG e movimento ambiental da cidade, e dois representantes de cada órgão público de meio ambiente atuante no município, sendo um de hierarquia superior, secretário ou superintendente, e um técnico com cargo de chefia e/ou coordenação, a saber: Ministério Público Federal (MPF) e Ministério Público Estadual (MPE), órgão fiscalizador da gestão pública para a garantia dos direitos da sociedade; Instituto Brasileiro do Meio Ambiente e dos Recursos Renováveis (IBAMA), Superintendência de Administração do Meio Ambiente (SUDEMA) e Secretaria Municipal de Meio Ambiente (SEMAM).

As entrevistas foram realizadas a partir de dois tipos de questionários semiestruturados, aplicados entre os meses de junho a agosto de 2012. Todas as entrevistas foram gravadas e transcritas, objetivando a fidelidade dos dados, bem como a captura de nuances, entonações e subjetividades relevantes.

$\mathrm{Na}$ terceira fase da pesquisa, selecionamos depoimentos complementares obtidos com alguns membros históricos do início do ambientalismo, em 1980, que continuam atuando em ONGs ou tornaram-se pessoas públicas. Optou-se por coletar depoimentos complementares sobre a formação do movimento ambientalista no Brasil e o seu desenvolvimento com os ambientalistas Fábio Feldman, João Paulo Capobianco e Mário Mantovani. 
Esses depoimentos visaram obter percepções e opiniões de militantes antigos da causa ambiental, para traçar uma perspectiva histórica e atual das ONGs, e do ambientalismo no Brasil. Os depoimentos foram coletados em entrevistas abertas, não estruturadas, norteadas por perguntas motivadoras iniciais, não sofrendo maiores interferências durante a sua realização. Essas perguntas buscaram complementar a dissertação e incluir a voz desses militantes históricos.

A proximidade tanto das ONGs ambientais quanto do poder público municipal, oferece riscos à interpretação das experiências vivenciadas. As motivações da pesquisa e sua longevidade abrangem momentos distintos para quem esteve presente, e participou de diversos momentos em ambos os lados - ONGs e poder público - fato que contribuiu bastante para a análise dos resultados.

\section{As ONGS ambientalistas x poder público}

As discussões acerca do na cidade de João Pessoa surgiu nos anos 1980, com a proibição da pesca às baleias, e atingiu seu ápice na conquista da proibição aos espigões na orla marítima, em 1989. Com o passar dos anos, o movimento desarticulou-se e passou a significar um pequeno grupo em prol de causas pontuais. Considerando este histórico, apresentamos alguns resultados obtidos por meio de tabelas, que revelam a assimetria entre as opiniões, e permitem comparar os dois grupos entrevistados. A iniciar com a indagação ao governo acerca da inclusão da temática ambiental em sua estrutura interna, que apontou a não priorização da questão ambiental por todas as fontes entrevistadas.

As estruturas governamentais e a formação dos elaboradores de políticas e projetos são fragmentadas, não havendo integração entre os órgãos e secretarias de governo, tanto municipal quanto estadual, o que dificulta a inserção do componente ambiental nos projetos e políticas públicas. Os gestores de outras secretarias se interessam pela temática ambiental, quando há algum benefício ou visibilidade. A retórica da sustentabilidade valoriza a ação, embora não reflita em consciência ambiental e ações concretas (ENTREVISTA 12, SEMAM, 2012). 
O meio ambiente é tratado como área relativamente recente, como se o nosso habitat não fosse o próprio meio ambiente, e como se dele não dependêssemos. Os analistas ambientais sempre precisam dar muitas explicações e associar biodiversidade, conservação e manejo de recursos naturais à sobrevivência humana, no intuito de convencer gestores e técnicos acerca da importância de incluir e considerar os aspectos ambientais nos projetos.

Para a SEMAM, há um predomínio de advogados e engenheiros na gestão pública, que trabalham com uma visão antiga e restrita de desenvolvimento, planejando ações e projetos como se nada houvesse no espaço a ser modificado. Obras e ações impactantes ao meio ambiente são propostas sem a participação de analistas ambientais, tampouco da sociedade, dissociando meio ambiente de secretarias como habitação, infraestrutura, planejamento, mobilidade etc.

Como o meio ambiente é interdisciplinar, ele dentro de uma prefeitura deveria ser também intersecretarial, algo inexistente hoje. Enquanto não houver uma horizontalidade na gestão pública, vai ser muito difícil haver o interesse e uma política ambiental, porque meio ambiente é uma área que não pode ser dissociada de uma política de habitação, saúde, educação etc. (ENTREVISTA 12, SEMAM, 2012).

Ambos os órgãos ambientais não são, muitas vezes, inseridos nos projetos, somente são requisitados quando há a necessidade do licenciamento ambiental, procedimento que não é compreendido como um instrumento de prevenção de impactos, e sim como uma exigência legal, um entrave. Não há uma associação do licenciamento à manutenção do aquífero, do solo, de uma drenagem natural que evite problemas de erosão, alagamentos, desmoronamentos, prevenção de acidentes geográficos ou em áreas de risco (ENTREVISTA 12, SEMAM, 2012).

Pelo contrário, geralmente as obras do poder público local são realizadas sem licenciamento ambiental, ou sendo este feito às pressas, para evitar a perda de recursos financeiros federais. Isso quando este não é feito às vésperas de uma inauguração, para subsidiá-la legalmente. Estudos de impacto ambiental, conforme obriga a legislação, não são solicitados a todos os empreendimentos, e os técnicos dos órgãos tampouco dispõem de tempo hábil para analisar os projetos e empreendimentos criteriosamente (ENTREVISTA 12, SEMAM, 2012). 
Alguns dos entrevistados afirmaram a inexistência de uma política ambiental em João Pessoa, tanto municipal como estadual. Em ambos os órgãos ambientais, nunca foi realizado um concurso público. Os cargos são ocupados por nomeação, e os atuais servidores efetivos foram transferidos de outras secretarias, demonstrando, assim, a necessidade de uma reforma administrativa. Isto se configura como uma negligência do poder público, pois a maioria dos funcionários são prestadores de serviços temporários ou estão em cargos comissionados, ambos voláteis, rotativos e com autonomia restrita.

O jargão de 'segunda cidade mais verde do mundo' demonstrou não representar uma maior preocupação capaz de mobilizar os atores a se relacionarem ou dialogarem em prol deste benefício comum, o que reflete na qualidade de vida da população, que nem sempre associa meio ambiente ao seu cotidiano e demandas por melhorias. A manutenção da arborização, o cuidado com as bacias hidrográficas e os projetos mais sustentáveis não são considerados ou priorizados pela gestão pública.

Quadro 1 - Situação das ONGs de João Pessoa

\begin{tabular}{|c|c|c|}
\hline & O discurso oficial sobre as ONGs & A autopercepção das ONGs \\
\hline $\begin{array}{l}\text { Como se veem } \\
\text { e atuam as } \\
\text { ONGs de João } \\
\text { Pessoa }\end{array}$ & $\begin{array}{l}\text { Pouca magnitude de atuação } \\
\text { Insignificantes para o governo } \\
\text { Ausentes do Orçamento } \\
\text { Democrático } \\
\text { Mantêm uma relação ambígua com } \\
\text { o governo } \\
\text { Defendem interesses privados ou } \\
\text { específicos de uma região } \\
\text { Ocupam instâncias de participação } \\
\text { (COPAM, COMAM), e participam } \\
\text { de audiências públicas }\end{array}$ & $\begin{array}{l}\text { Desarticuladas e isoladas } \\
\text { Desconhecidas } \\
\text { Desunidas } \\
\text { Possuem interesses políticos } \\
\text { Enfraquecidas e desorganizadas } \\
\text { Sem divulgação de suas ações } \\
\text { Sem respaldo da sociedade e } \\
\text { com dificuldade em mobilizá-la }\end{array}$ \\
\hline
\end{tabular}

Fonte: Pesquisa de campo. Castro (2012). 
De acordo com o quadro 1, podemos inferir que há similaridades nos discursos no que tange a situação atual das ONGs. A desarticulação, a desunião e o desconhecimento delas, perante a sociedade, são características apontadas tanto por elas mesmas, quanto pelo governo. Apesar de estarem todas trabalhando pelo meio ambiente, as ONGs percebem que caminham distantes, pois acreditam tratar de causas específicas. Porém analisamos que há problemas de relacionamento interpessoal dos membros.

A incipiente divulgação das ações desenvolvidas pelas ONGs prejudica o intercâmbio de conhecimento, entre elas, e delas para com a sociedade. As ONGs se comunicam pouco entre si, muitas não possuem um site na internet, materiais gráficos de suas atividades ou utilizam-se de outros meios de comunicação. Assim, realizam trabalhos desconhecidos e que não se traduzem para a maioria da sociedade.

As ONGs não têm muito respaldo da sociedade. São vistas como um grupo de pessoas querendo fazer algo, mas não tem uma conexão como sendo a sociedade. São sempre as mesmas pessoas, tentando fazer algo, mudar uma realidade, e a sociedade continua apática. Quando se organizam passeatas ou movimentos, a participação é sempre dos mesmos indivíduos, a sociedade sabe, acha legal, mas não se sente incluída. Estamos no momento ainda de sensibilizar as pessoas e imbuir a ideia de que elas também precisam participar. A sociedade é parte disso. (ENTREVISTA 1, Guajiru, 2012).

A SEMAM apontou uma resistência dos integrantes das ONGs, em dialogar com o governo, além de se comportarem de maneira "preconceituosa", quando os ativistas entram para a gestão pública. Elas tratam esta relação como ambígua e incompatível "Você não pode ser .gov e ao mesmo tempo .org" (ENTREVISTA 8, APAN, 2012). Assim, mantém-se um distanciamento e uma crítica constante em ambos os lados, dificultando o diálogo e a parceria para resolução dos conflitos ambientais.

A pesquisa também encontrou movimentos ambientalistas que realizam ações similares ou complementares, mas que não se comunicam entre si devido a conflitos pessoais, ou posicionamentos contrários de alguns membros acerca de casos ocorridos no passado da relação com o poder público. Assim, aqueles que foram da gestão pública ou a favor de alguma ação por ela proposta, são vistos como inimigos do movimento naquele momento, e sentimentos de pertencimento se mesclam na relação pelo bem 
comum, embora estas pessoas se alternem em momentos de ocupação de cargos públicos.

A formação de redes de fruição e conhecimento poderia contribuir para a união destas e o compartilhamento de informações sobre suas ações. Na Paraíba, seria interessante se constituir uma rede de ONGs com um fórum permanente de discussões, com capilaridade e o auxílio das redes sociais, como uma forma de articulação e fruição das informações. Desta forma, o ciberativismo virtual e o ativismo presencial por causas locais poderiam se ampliar, auxiliando na união das entidades e numa maior participação da sociedade em prol da defesa do meio ambiente.

Questionamos como as ONGs e o poder público avaliam a relação entre eles, na gestão ambiental, conforme o quadro 2. Com o governo municipal, a relação é difícil, conturbada e desgastada, permeada por divergências. Meio ambiente não se tornou prioridade interna do governo. Por outro lado, o impulso na economia, provocado pela construção civil, interfere diretamente nos atributos ambientais de João Pessoa. Os espaços valorizados e destinados ao setor foram exatamente as áreas verdes, alvos de grandes empreendimentos.

A expansão demográfica traduz-se em desmatamento para construção de novas áreas, tanto para empreendimentos luxuosos como populares, tratando áreas remanescentes da Mata Atlântica como espaços vazios a serem ocupados, construídos e valorizados economicamente, e não áreas ricas em biodiversidade que necessitam de conservação e promovem qualidade de vida. Nestes espaços são realizados projetos distantes do conceito de sustentabilidade, protelando problemas decorrentes da escassez de recursos naturais para um futuro próximo.

A expansão do movimento ambientalista em João Pessoa, em busca por uma maior adesão da sociedade e de gestores públicos, ainda é incipiente. As conquistas das ONGs no passado permanecem na memória da população, porém, para a SUDEMA, a política desenvolvimentista acaba influenciando as prioridades de governo e inviabilizando conquistas ambientais. Ainda é preciso educar e sensibilizar os gestores públicos, bem como a sociedade, acerca da importância e emergência da crise ambiental. 
Quadro 2 - Diálogo e relação das ONGs com o poder público

\begin{tabular}{|c|c|c|}
\hline & $\begin{array}{l}\text { O discurso oficial sobre as } \\
\text { ONGs }\end{array}$ & as ONGs \\
\hline $\begin{array}{lr}\text { Diálogo } & \text { e } \\
\text { relação } & \text { das } \\
\text { ONGs com o } \\
\text { poder público no } \\
\text { período de } 2005 \\
\text { a } 2012\end{array}$ & $\begin{array}{l}\text { Pontual devido ao ambientalismo } \\
\text { ser pequeno } \\
\text { Conflituosa e pontual } \\
\text { Retrocedeu } \\
\text { Conturbada, } \\
\text { desprestigiadas } \\
\text { Desgastada por conta da } \\
\text { politicagem } \\
\text { Melhorou, variando com os } \\
\text { gestores } \\
\text { Evoluiu com popularização e } \\
\text { instrumentos como o OD. } \\
\text { Parceria e ocupando instâncias de } \\
\text { participação }\end{array}$ & $\begin{array}{l}\text { Incipiente } \\
\text { Precária, meio ambiente não é } \\
\text { valorizado } \\
\text { Inexistente } \\
\text { Precária, deslegitimando as ONGs } \\
\text { Difícil devido a questão partidária } \\
\text { Precário, variando com os } \\
\text { gestores } \\
\text { Difícil, porém melhorou com o } \\
\text { OD } \\
\text { Difícil, e quando ocorre, os } \\
\text { avanços práticos são poucos } \\
\text { Melhorou, com as instâncias de } \\
\text { participação }\end{array}$ \\
\hline
\end{tabular}

Fonte: pesquisa de campo. Castro, (2012).

A falta de discussões mais amplas nas instâncias de participação, incluindo temas variados, é outro fator que contribui para uma visão restrita e parcial do meio ambiente dentro do governo e na discussão com a sociedade, segundo o IBAMA. Esta opinião é validada pela observação das reuniões dos conselhos, que se restringem às pautas em torno da aprovação de licenças ambientais.

A relação do governo com as ONGs é tensa e precária, além de ser prejudicada também pela velocidade dos impactos ambientais, e o tempo de reação das ONGs diante 
deles. Os posicionamentos contrários às ações do governo são recebidos a contragosto pelos gestores públicos, que continuam a desconsiderar o componente ambiental em projetos futuros, ao invés de perceber sua importância e atuar, assim, em parceria e diálogo com as ONGs, que afinal representam a sociedade.

Há uma visão errônea que emperra no governo de que somos inimigas do sistema. Na verdade, as ONGs estão ai pra realizar ações que deveriam ser obrigações do governo, mas que ele não realiza por negligência ou falta de perna, e as ONGs devem ser vistas como parceiras. Mas infelizmente quando criticamos, passamos a ser excluídas das discussões. Muitas vezes, as ONGs são usadas quando o governo precisa e no momento que contestamos a ação governamental, passamos a ser inimigas, deixamos de ser alguém que pode contribuir com uma crítica ou solução alternativa. A gente percebe ainda muito preconceito do governo com relação ao que são as ONGs e o que elas podem contribuir. (ENTREVISTA 1, Guajiru, 2012).

A cultura política local também apresenta elementos que dificultam esta relação, especialmente pela dificuldade em separar a política de desenvolvimento, da política de grupos partidários. As relações partidárias são fortes na Paraíba, e correspondem à relação clientelista ainda existente no híbrido modelo de gestão tradicional e inovador.

A respeito do impacto das ONGs ambientalistas, na formulação de políticas públicas, a maioria afirmou ser relativo, pontual, pequeno e até mesmo inexistente (tabela 3), embora a proibição dos espigões configure como uma conquista ícone das ONGs.

As instâncias de participação são poucas, bem como a inserção nelas é limitada, diante do direcionamento exclusivo na aprovação de licenças ambientais, muitas vezes apenas validando os processos, e não analisando criticamente os impactos. Apesar de ocupar estes espaços, as ONGs ficam restritas à pauta proposta pelo poder público, e a sociedade desconhece a importância de participar e cobrar discussões mais amplas, além de não ser informada das decisões tomadas. 
Quadro 3 - Impacto das ONGs em políticas públicas, com exemplos positivos

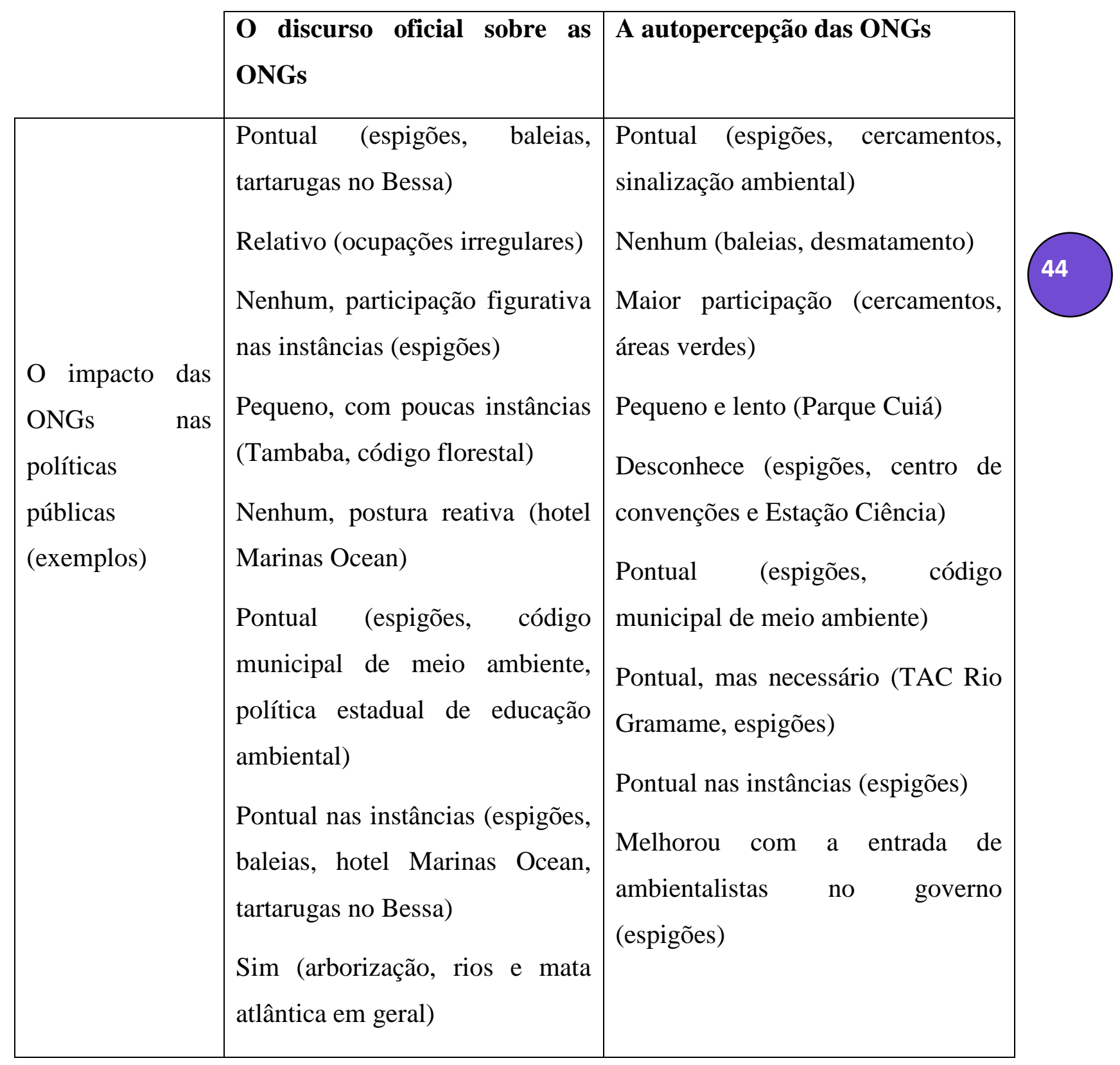

Fonte: Pesquisa de campo. Castro (2012).

Para a maioria das fontes entrevistadas, a atuação das ONGs, em João Pessoa, impediu maiores impactos ambientais. Entretanto, conforme afirmou o MPF, atualmente a ação das ONGs é reativa diante das agressões ambientais, buscando salvaguardar a qualidade ambiental ainda presente em João Pessoa. Lamentavelmente, como constata um ambientalista: "A atuação do movimento ambientalista hoje é para 
evitar retrocessos, e não para ampliar conquistas" (Entrevista 22, Mario Mantovani, SOS Mata Atlântica).

As ONGs recorrem frequentemente aos Ministérios Públicos (MPs), para garantir alguma atitude diante dos impactos. Tanto o Ministério Público Estadual, como Federal, afirmaram que o poder público dificulta o diálogo com as ONGs, acontecendo quando os mesmos são obrigados judicialmente ou quando perdem ações. Ainda ocorrem medidas repressoras para pequenos, e flexibilidades para os grandes impactos ambientais, um paradoxo histórico e cultural que culmina com a natureza como maior perdedora.

Por fim, podemos inferir que a relação das ONGs ambientalistas com o poder público em João Pessoa ainda é complicada e permeada por interesses difusos e pela cultura política local, além do diálogo ser dificultado. Por um lado, o município está em crescimento acelerado, por meio do que compreende por desenvolvimento; e por outro, possui um diferencial ambiental relevante, uma disputa inversamente proporcional, pautada na disparidade de interesses e na desvantagem de forças.

Nas instâncias de participação, as ONGs são tratadas como inimigas, por se posicionarem contrárias às intenções do governo, porém não possuem força nas decisões tomadas, segundo o IBAMA. A SUDEMA ressaltou que o Estado oferece poucos espaços de participação pública. No COPAM, por exemplo, a APAN fica isolada, pois a ONG ambiental possui um único voto, enquanto o CREA possui cinco assentos. Assim, ocorre uma relação conflituosa, já que a ONG sempre aponta reivindicações, e perde as votações, participando de maneira mais figurativa do que decisiva, segundo o IBAMA.

O Ministério Público Estadual e Federal percebem estes espaços como pouco democráticos, muito políticos e não técnicos, haja vista a disparidade nos assentos e as indicações e posicionamentos políticos. Tais instâncias são de controle social político, com a presidência sempre do órgão governamental. Na opinião do MPF, não há espaços mais amplos para participação, e isto prejudica o equilíbrio das decisões públicas. 


\section{Considerações finais}

O ambientalismo e o poder público em João Pessoa encontram-se distantes. De acordo com a pesquisa de campo, inexiste uma relação e diálogo com vias à promoção do interesse coletivo, como também os conflitos não são compreendidos como partes integrantes desse diálogo. Diante do panorama autoritário do governo, a sociedade, em geral, posiciona-se de maneira distante e pouco participativa das ações promovidas pelas ONGs, não compreendendo o meio ambiente como patrimônio coletivo e incorporando cada vez mais a individualidade em seus posicionamentos. Atitudes e hábitos mais sustentáveis são pontuais e pouco percebidos no município.

A gestão pública planeja projetos e ações de maneira isolada, não incluindo o componente ambiental e ocasionando problemas futuros, principalmente por dissociar meio ambiente de áreas estruturantes. Transferem-se problemas ambientais decorrentes de obras impactantes para os próximos gestores públicos. Os gestores se comportam de maneira temporal, contabilizando e planejando suas ações para os quatro anos de governo. Assim, projetos mais longos e estruturantes, de transformação social e ambiental de uma cidade são evitados, pois não darão a visibilidade desejada para um futuro pleito eleitoral. Desta forma, há grandes déficits ambientais nas cidades brasileiras, que somente se mobilizam para realizar ações concretas, quando da iminência de catástrofes ambientais ou problemas emergenciais, a exemplo da erosão na Falésia do Cabo Branco, que recentemente figurou em noticiário nacional. Soma-se a isto, a descontinuidade de governos e a rotatividade de servidores públicos comissionados ou temporários, o que inviabiliza projetos em médio e longo prazo, mais pertinentes para a velocidade de resiliência da natureza.

O meio ambiente ainda não foi incorporado de maneira transversal no interior do poder público, e também não é compreendido como estando presente em todas as áreas, desde o espaço em que vivemos até as nossas necessidades, como ar, alimentos, água, descanso, conforto térmico, entre outros. A dissociação do componente ambiental alcança também a incompreensão da sociedade, que formula suas demandas de maneira pontual e isolada, e os governantes contemplam menos ainda a abrangência da natureza nas políticas públicas.

RPI Revista de Pesquisa Interdisciplinar, Cajazeiras, v. 3, n. 1, 28-48, jan/jul. de 2018. 
Confrontando os dados obtidos nas pesquisas, encontramos interesses e percepções convergentes, tanto dos membros das ONGs, como do governo. Estas, se dialogadas e compartilhadas, podem contribuir para uma parceria mais efetiva entre esses atores, e consequentemente, numa maior presença do componente ambiental, dentro das estruturas de governo, e deste, no apoio às ONGs atuantes no município.

Por mais que as ONGs promovam o conflito, por apontar equívocos da gestão pública, alguns gestores e funcionários públicos também percebem e reconhecem a existência destes equívocos. Os posicionamentos críticos apontaram para uma preocupação com os atributos ambientais que promovem qualidade de vida, o que se configura como um elo convergente de ligação entre ONGs e o poder público. Pensar no bem maior, no patrimônio comum e na coletividade é uma meta a ser enfatizada e compartilhada entre os ativistas ambientais, sejam eles provenientes das ONGs, ou atuantes no poder público. A natureza é que se beneficiará desta parceria entre as pessoas que têm consciência e atuam em sua defesa e proteção. Afinal a cidade é de todos e para todos, e sua qualidade de vida depende dessa união.

\section{Referências bibliográficas}

AVRITZER, Leonardo. A participação social no nordeste. Belo Horizonte: Editora da UFMG, 2007.

CASTRO, Vivian Maitê. Ambientalismo em João Pessoa/PB: A participação da sociedade nas políticas públicas (2005-2012). 2013. 118 f. Dissertação (Mestrado em Desenvolvimento e Meio Ambiente) - Universidade Federal da Paraíba, João Pessoa, 2013.

DAMATTA, Roberto. O que faz do Brasil, Brasil? Rio de Janeiro: Rocco, 1986. FERNANDES, Antônio Sérgio Araújo. Gestão municipal e participação social no Brasil: a trajetória e recife e Salvador (1986-2000). São Paulo: Fapesp, 2004. GOHN, Maria da Glória. Conselhos gestores e participação sociopolítica. São Paulo: Cortez, 2011. Vol. 32. 
MOISÉS, José Álvaro. Democratização e cultura política de massas no Brasil. São Paulo: CEDEC, 1992. Revista Lua Nova, ${ }^{\circ} 26$. Disponível em: <http://www.scielo.br/scielo.php?pid=S0102-64451992000200002\&script=sci_arttext $>$. Acesso em: 20 out. 2012.

Os brasileiros e a democracia: bases sócio-políticas da legitimidade democrática. São Paulo: Ática, 1995.

MORESI, Eduardo (org). Metodologia da Pesquisa. Brasília: UCB, 2003. Disponível em: <http://www.inf.ufes.br/ pdcosta/ensino/2010-2-metodologia-de-pesquisa/ MetodologiaPesquisa-Moresi2003.pdf>. Acesso em 20 ago. 2012.

ROLNIK, Raquel; SOMEKH, Nadia. Governar as metrópoles: dilemas da recentralização. São Paulo: Revista São Paulo em Perspectiva, 2000. Vol.14. N4.

Disponível em: <http://www.scielo.br/scielo.php?pid=S0102-

$\underline{88392000000400009 \& \text { script=sci_arttext } \& \text { tlng=pt }>}$. Acesso em: 23 nov. 2012.

SILVA, Gustavo Tavares da. Eleições 2010: impressões na Paraíba. João Pessoa: Editora Universitária da UFPB, 2011. . Gestão pública e transformação social no Brasil. In: Participação cidadã: novos conceitos e metodologias. Fundação Konrad Adenauer. Fortaleza: Expressão Gráfica e Editora, 2004. Disponível em: <http://www.kas.de/db_files/dokumente/7_dokument_dok_pdf_6545_1.pdf\#page=60 $>$. Acesso em: 27 nov. 2013.

SILVA, Christian Luiz da; Souza-Lima, José Edmilson. Políticas públicas e indicadores para o desenvolvimento sustentável. São Paulo: Saraiva, 2010. SORJ, Bernardo. A nova sociedade brasileira. $3^{\text {a }}$ edição revista. Rio de Janeiro: Jorge Zahar Editor, 2006.

TEIXEIRA, Elenaldo Celso. Dimensões da participação cidadã. Salvador: Caderno CRH. n 26/27, p. 179-209, jan/dez, 1997. Disponível em:

http://www.cadernocrh.ufba.br/viewarticle.php?id=198\&locale=it\&locale=en. Acesso em: 20 out. 2013. 